\title{
Fe deficiency differentially affects the vacuolar proton pumps in cucumber and soybean roots
}

\section{Marta Dell'Orto*, Patrizia De Nisi, Gianpiero Vigani and Graziano Zocchi}

Dipartimento di Scienze Agrarie, Alimentari e Ambientali, Università degli Studi di Milano, Milano, Italy

\section{Edited by:}

Jean-Francois Briat, Centre National de la Recherche Scientifique, France

\section{Reviewed by:}

Javier Abadía, Consejo Superior de Investigaciones Cientificas, Spain Richard Bligny, Commissariat à

I'Energie Atomique et aux Energies

Alternatives, France

${ }^{*}$ Correspondence:

Marta Dell'Orto, Dipartimento di Scienze Agrarie, Alimentari e Ambientali, Università degli Studi di Milano, Via Celoria 2, 20133 Milano, Italy

e-mail: marta.dellorto@unimi.it
Iron uptake in dicots depends on their ability to induce a set of responses in root cells including rhizosphere acidification through $\mathrm{H}^{+}$extrusion and apoplastic $\mathrm{Fe}(\mathrm{III})$ reduction by $\mathrm{Fe}(\mathrm{III})$-chelate reductase. These responses must be sustained by metabolic rearrangements aimed at providing the required $\mathrm{NAD}(\mathrm{P}) \mathrm{H}, \mathrm{ATP}$ and $\mathrm{H}^{+}$. Previous results in Fe-deficient cucumber roots showed that high $\mathrm{H}^{+}$extrusion is accompanied by increased phosphoenolpyruvate carboxylase (PEPC) activity, involved in the cytosol $\mathrm{pH}$-stat; moreover ${ }^{31} \mathrm{P}$ NMR analysis revealed increased vacuolar $\mathrm{pH}$ and decreased vacuolar [inorganic phosphate (Pi)]. The opposite was found in soybean: low rhizosphere acidification, decreased PEPC activity, vacuole acidification, and increased vacuolar [Pi]. These findings, highlighting a different impact of the Fe deficiency responses on cytosolic $\mathrm{pH}$ in the two species, lead to hypothesize different roles for $\mathrm{H}^{+}$and $\mathrm{Pi}$ movements across the tonoplast in $\mathrm{pH}$ homeostasis. The role of vacuole in cytosolic $\mathrm{pH}$-stat involves the vacuolar $\mathrm{H}^{+}$-ATPase (V-ATPase) and vacuolar $\mathrm{H}^{+}$-pyrophosphatase (V-PPase) activities, which generating the $\Delta \mathrm{pH}$ and $\Delta \psi$, mediate the transport of solutes, among which $\mathrm{Pi}$, across the tonoplast. Fluxes of $\mathrm{Pi}$ itself in its two ionic forms, $\mathrm{H}_{2} \mathrm{PO}_{4}{ }^{-}$predominating in the vacuole and $\mathrm{HPO}_{4}{ }^{2-}$ in the cytosol, may be involved in $\mathrm{pH}$ homeostasis owing to its $\mathrm{pH}$-dependent protonation/deprotonation reactions. Tonoplast enriched fractions were obtained from cucumber and soybean roots grown with or without Fe. Both V-ATPase and V-PPase activities were analyzed and the enrichment and localization of the corresponding proteins in root tissues were determined by Western blot and immunolocalization. V-ATPase did not change its activity and expression level in response to Fe starvation in both species. V-PPase showed a different behavior: in cucumber roots its activity and abundance were decreased, while in Fe-deficient soybean roots they were increased. The distinct role of the two $\mathrm{H}^{+}$pumps in Pi fluxes between cytoplasm and vacuole in Fe-deficient cucumber and soybean root cells is discussed.

Keywords: V-ATPase, V-PPase, Fe deficiency, cucumber, soybean

\section{INTRODUCTION}

Among Strategy I plants (dicots and non-graminaceous monocots) there is an inter- and intra-specific variability in susceptibility to lime-induced Fe deficiency, despite a similar demand for Fe. This variability is strongly related to the ability of plants to enhance the activities involved in the so-called reduction based Strategy I (Marschner et al., 1986; Schmidt, 2006; Kim and Guerinot, 2007; Ivanov et al., 2012), residing at the root cell plasma membrane (PM), which consists of three main steps: (1) acidification of the root apoplast and rhizosphere, mainly due to the enhanced $\mathrm{H}^{+}$extrusion driven by the plasma membrane $\mathrm{H}^{+}$-ATPase (PMATPase); (2) reduction of the extracellular $\mathrm{Fe}^{3+}$ to $\mathrm{Fe}^{2+}$, which is the only form transported into the root by these species, by means of $\mathrm{Fe}(\mathrm{III})$-chelate reductase (FC-R) which utilizes $\mathrm{NAD}(\mathrm{P}) \mathrm{H}$ as reducing substrate; (3) $\mathrm{Fe}^{2+}$ transport into the root symplast by IRT1, a member of the ZIP family.

The variability found among plants in the ability to induce these activities under Fe deficiency is particularly wide for $\mathrm{H}^{+}$extrusion (Schmidt, 1999) rather than for FC-R, since Fe(III) reduction is an obligatory step in Fe acquisition by Strategy I plants; in fact, differences were found among differently tolerant species also in the ability to modify the metabolism in order to provide $\mathrm{NAD}(\mathrm{P}) \mathrm{H}, \mathrm{ATP}$ and $\mathrm{H}^{+}$necessary to sustain the reduction-based response (Zocchi, 2006).

Moreover, a wide variability has been also found among dicots in the production and secretion of compounds facilitating the uptake of Fe, such as flavins and phenolics (Rodríguez-Celma et al., 2013).

In Fe-deficient cucumber plants the high induction of the Strategy I responses is concomitant with the increase in carbohydrate catabolism, through the up-regulation of glycolysis and oxidative pentose phosphate pathway (Rabotti et al., 1995; Espen et al., 2000), providing ATP and reducing equivalents. Moreover, in such conditions, phosphoenolpyruvate carboxylase (PEPC) activity results to be enhanced even more than the primary responses (De Nisi and Zocchi, 2000), leading to PEP consumption (with further increase in the glycolysis rate) and synthesis of organic acids, which are protogenic. Indeed, PEPC activity has been 
recognized to play a fundamental role in balancing cytoplasmic pH (Davies, 1973), which, in Fe-deficient cucumber roots, is subject to alkalization due to the exceptionally high rate of $\mathrm{H}^{+}$extrusion. Intriguingly, a strong PEPC induction upon $\mathrm{Fe}$ deficiency was found in plants with high $\mathrm{H}^{+}$extrusion activity such as sugar beet (López-Millán et al., 2000), bean (Bienfait et al., 1989), Capsicum annuum (Landsberg, 1986). On the contrary, in plants which do not induce $\mathrm{H}^{+}$-ATPase activity under Fe starvation, or which induce it at a low rate such as Medicago ciliaris (M'sehli et al., 2009a,b) or soybean (Zocchi et al., 2007), PEPC activity and expression level only are weakly or not induced.

Thus, comparing the responses to Fe deficiency in two dicotyledonous plants, cucumber, and soybean, it arises that their different ability to induce the Strategy I responses and in particular apoplast acidification, is accompanied by different degree in the activation of the carbohydrate catabolism, especially in the induction of PEPC (De Nisi and Zocchi, 2000; Zocchi et al., 2007). Accordingly, data from in vivo ${ }^{31} \mathrm{P}-\mathrm{NMR}$ studies conducted on Fe deficient roots of these two species (Espen et al., 2000; Zocchi et al., 2007) showed some interesting differences: (a) the cytoplasm pH was kept almost constant in root cells of both species, suggesting that efficient $\mathrm{pH}$-stat mechanisms are functioning; conversely, the vacuolar $\mathrm{pH}$ increased in cucumber, characterized by active $\mathrm{H}^{+}$extrusion to the apoplast, while it was lowered in soybean roots under Fe deficiency; this is consistent with the role of vacuole in cytosolic $\mathrm{pH}$ homeostasis under various stresses (Martinoia et al., 2007); (b) moreover, while in Fe-deficient cucumber roots a dramatic fall in the vacuolar inorganic phosphate $(\mathrm{Pi})$ concentration occurred, soybean showed a strong increase of the $\mathrm{Pi}$ concentration in the vacuole. These findings led Zocchi et al. (2007) to hypothesize that, besides the already established role of PM-ATPase and PEPC in the pH-stat mechanism under Fe deficiency (Zocchi, 2006 and references therein), also the movements of $\mathrm{Pi}$ in its two inorganic forms, $\mathrm{H}_{2} \mathrm{PO}_{4}{ }^{-}$predominating in the vacuole and $\mathrm{HPO}_{4}{ }^{2-}$ in the cytosol, across the tonoplast could cooperate in balancing the cytosolic $\mathrm{pH}$, thanks to the buffering activity exerted by its $\mathrm{pH}$-dependent protonation/deprotonation reactions. Little is known about Pi transport across the tonoplast, as no carriers nor channels have been identified so far. What is known is that its entrance into the vacuole has been demonstrated to be driven by the $\mathrm{H}^{+}$gradient generated across the tonoplast by the two vacuolar proton pumps (Massonneau et al., 2000; Ohnishi et al., 2007): the vacuolar $\mathrm{H}^{+}$-ATPase (V-ATPase, EC 3.6.3.14) and the vacuolar $\mathrm{H}^{+}$-pyrophosphatase (V-PPase, EC 3.6.1.1), which actively transport $\mathrm{H}^{+}$inside the vacuolar lumen hydrolyzing ATP and inorganic pyrophosphate (PPi), respectively, thus generating the electrochemical potential difference $(\Delta \mathrm{pH}$ and $\Delta \psi)$ which mediates the secondary active transport of solutes (among which $\mathrm{Pi}$ ) across the tonoplast (Maeshima, 2001; Hedrich and Marten, 2006; Schumacher, 2006).

Thus, the activity and expression of V-ATPase and V-PPase are expected to be differently regulated in cucumber and soybean in response to Fe deficiency. For this reason, the aim of this work was to characterize how the activities of the vacuolar proton pumps change in cucumber and soybean roots grown under Fe deficiency.

\section{MATERIALS AND METHODS PLANT MATERIAL AND GROWTH CONDITIONS}

Seeds of cucumber (Cucumis sativus L., cv. Marketmore 76) and soybean (Glycine max L. cv. Elvir from Pioneer, Italy) were sown in wet agriperlite and allowed to germinate in the dark at $26^{\circ} \mathrm{C}$ for 3 days (cucumber) or $18^{\circ} \mathrm{C}$ for 6 days (soybean). Seedlings were transferred to a nutrient solution with the following composition: $2 \mathrm{mM} \mathrm{Ca}(\mathrm{NO})_{3}, 0.75 \mathrm{mM} \mathrm{K}_{2} \mathrm{SO}_{4}, 0.65 \mathrm{mM} \mathrm{MgSO}_{4}, 0.5 \mathrm{mM}$ $\mathrm{KH}_{2} \mathrm{PO}_{4}, 10 \mu \mathrm{M} \mathrm{H}_{3} \mathrm{BO}_{3}, 1 \mu \mathrm{M} \mathrm{MnSO}_{4}, 0.5 \mu \mathrm{M} \mathrm{ZnSO}_{4}, 0.05 \mu \mathrm{M}$ $\left(\mathrm{NH}_{4}\right) \mathrm{Mo}_{7} \mathrm{O}_{24}$, and $0.1 \mathrm{mM}$ Fe-EDTA (when added). The $\mathrm{pH}$ was brought to 6.0-6.2 with $\mathrm{NaOH}$. Plants in hydroponic cultures were maintained in a growth chamber with a day/night regime of $16 / 8 \mathrm{~h}$ at $24 / 18^{\circ} \mathrm{C}$ and a PPFD of $200 \mu \mathrm{mol} \mathrm{m}^{-2} \mathrm{~s}^{-1}$. The nutrient solution was changed weekly.

\section{ISOLATION OF TONOPLAST-ENRICHED VESICLES}

Vacuolar membrane vesicles were isolated from roots of plants grown for 8 days (cucumber) and 11 days (soybean) in the presence or in the absence of Fe, according to Rea and Poole (1985) with some modifications. About $25 \mathrm{~g}$ of roots were homogenized using mortar and pestle in $4 \mathrm{~mL} / \mathrm{g}$ (fresh weight) of a buffer containing $250 \mathrm{mM}$ sorbitol, $25 \mathrm{mM}$ Tris-Mes pH 7.4, and $5 \mathrm{mM} \mathrm{Na-EDTA.}$ Just prior to use, $1 \mathrm{mM}$ DTT and $2 \mathrm{mM}$ PMSF were added to the buffer. The homogenate was filtered through four layers of gauze and centrifuged at $12,000 \mathrm{~g}$ for $15 \mathrm{~min}$. The supernatant was then centrifuged at $80,000 \mathrm{~g}$ for $30 \mathrm{~min}$. The pellet was resuspended in $3 \mathrm{~mL}$ of a resuspension medium (RM) containing 1.1 M glycerol, $2.5 \mathrm{mM}$ Tris-Mes pH 7.4, $5 \mathrm{mM}$ Na-EDTA, $1 \mathrm{mM}$ DTT, and $0.1 \mathrm{mM}$ PMSF and layered over a 10/23\% discontinuous sucrose gradient prepared in RM. After centrifugation at 80,000 $g\left(\mathrm{r}_{\max }\right)$ for $2 \mathrm{~h}$ in a swinging bucket rotor (SW40), vesicles sedimented at the interface between 10 and 23\% sucrose were collected, diluted with three volumes of RM and centrifuged at $80,000 \mathrm{~g}$ for $30 \mathrm{~min}$. The pellet was finally resuspended in about $150 \mu \mathrm{L}$ of RM. The vesicles were either used immediately or frozen under liquid $\mathrm{N}_{2}$ and stored at $-80^{\circ} \mathrm{C}$ until use. Protein concentration was determined by the Bradford method using BSA as the standard (Bradford, 1976).

\section{MEASUREMENT OF $\mathrm{H}^{+}$-ATPase AND $\mathrm{H}^{+}$-PPase ACTIVITIES}

The activity of the V-ATPase was measured as the rate of ADPdependent NADH oxidation in a coupled lactate dehydrogenasepyruvate kinase reaction and ATP-regenerating system at $25^{\circ} \mathrm{C}$ according to Ward and Sze (1992) with modifications. The reaction mixture ( $1 \mathrm{~mL}$ ) contained $25 \mathrm{mM}$ MOPS-BTP buffer $\mathrm{pH}$ 7.0, $50 \mathrm{mM} \mathrm{KCl}, 250 \mathrm{mM}$ sucrose, $3 \mathrm{mM}$ ATP, $1 \mathrm{mM}$ PEP, $0.25 \mathrm{mM}$ $\mathrm{NADH}, 4.5 \mathrm{mM} \mathrm{MgSO}_{4}, 0.015 \%$ Lubrol, $6 \mathrm{U} / \mathrm{mL}$ pyruvate kinase and $12 \mathrm{U} / \mathrm{mL}$ lactate dehydrogenase, $20 \mu \mathrm{g}$ membrane protein. Sodium molybdate $0.1 \mathrm{mM}$ was added to the reaction medium to inhibit acid phosphatase activity. The rate of NADH oxidation was measured as the decrease in $\mathrm{A}_{340}$ with time. The assay was preformed in the presence and in the absence of $50 \mathrm{mM} \mathrm{K}$-nitrate (a specific inhibitor of the V-type ATPase) and the difference between these two activities was attributed to the vacuolar ATPase. Analog results were obtained using bafilomycin as V-ATPase inhibitor. The degree of purity of the tonoplast membrane preparations was also assessed by measuring marker enzymes for mitochondria 
(azide-sensitive $\mathrm{H}^{+}$-ATPase) and PM (vanadate-sensitive $\mathrm{H}^{+}$ATPase) contamination according to Rabotti and Zocchi (1994): around $60 \%$ of the total activity was nitrate-sensitive (tonoplast), the remaining $40 \%$ was almost totally vanadate-sensitive activity, while the azide-sensitive activity was negligible.

The activity of the V-PPase was measured as the rate of liberation of Pi from PPi in a reaction volume of $250 \mu \mathrm{l}$ by the Ames (1966) method. According to Rea and Poole (1985) with some modifications, the assay medium consisted of $15 \mu \mathrm{g}$ membrane protein, $40 \mathrm{mM}$ Tris-Mes pH 8.0, $50 \mathrm{mM} \mathrm{KCl,} \mathrm{0.1 \%} \mathrm{Lubrol,} 3 \mathrm{mM}$ $\mathrm{Na}-\mathrm{PPi}$ and $3 \mathrm{mM} \mathrm{MgSO} 4,0.1 \mathrm{mM} \mathrm{Na} 2 \mathrm{MoO}_{4}$ (to inhibit acid phosphatase activity). PPase activity was calculated as half the rate of Pi liberation ( $1 \mathrm{~mol}$ of $\mathrm{PPi}=2 \mathrm{~mol}$ of $\mathrm{Pi}$ ).

\section{WESTERN BLOTTING ANALYSIS}

Tonoplast enriched fractions extracted from roots of plants grown in the presence and in the absence of Fe were loaded on a discontinuous SDS-polyacrylamide gel (3.75\% [w/v] acrylamide stacking gel, and $10 \%[\mathrm{w} / \mathrm{v}]$ acrylamide separating gel). For each sample $10 \mu \mathrm{g}$ of total protein were loaded.

After SDS-PAGE, the electrophoretic transfer to nitrocellulose membrane filters (Sigma) was performed using a semi-dry blotting system in $10 \mathrm{mM}$ cyclohexylamino-1-propane sulphonic acid ( $\mathrm{pH} 11.0$ with $\mathrm{NaOH})$ and $10 \%(\mathrm{v} / \mathrm{v})$ methanol for $1.5 \mathrm{~h}$ at room temperature at $0.8 \mathrm{~mA} \mathrm{~cm}^{-2}$. After blotting, the membrane was incubated for $1 \mathrm{~h}$ in TBS-T buffer (Tris Buffered Saline, $0.1 \%$ Tween-20, 5\% commercial dried skimmed milk). Polyclonal antibodies raised against a $100 \mathrm{kDa}$ peptide (ELVEINANNDKLQRSYNELC) corresponding to the V-ATPase subunit a and a $73 \mathrm{kDa}$ peptide (CDLVGKIERNIPEDDPRN) corresponding to the V-PPase (Maeshima and Yoshida, 1989; Maeshima, 2001; Kobae et al., 2004) were used. The incubation in primary antibody, diluted 1:1500 in TBS, was carried out for $2 \mathrm{~h}$ at room temperature. After rinsing with TBS-T, membranes were incubated at room temperature for $2 \mathrm{~h}$ with a 1:10000 diluted secondary antibody (alkaline phosphatase-conjugated anti-rabbit IgG, Sigma). After rinsing in TBS-T membranes were incubated in 5-bromo4-chloro-3-indolyl phosphate and nitroblue tetrazolium (FAST BCIP/NBT, Sigma).

\section{IMMUNOLOCALIZATION OF VACUOLAR PROTON PUMPS}

Apical segments from roots of both 8-day-old cucumber and 11day-old soybean plants grown in the presence and in the absence of Fe were fixed at $4^{\circ} \mathrm{C}$ in $100 \mathrm{mM}$ sodium phosphate buffer $(\mathrm{pH} 7.0)$ containing $4 \%$ paraformaldehyde $(\mathrm{w} / \mathrm{v})$, then dehydrated through an ethanol-tertiary butanol series and embedded in paraffin (Paraplast plus, Sigma) as described by Dell'Orto et al. (2002). Serial sections of $5 \mu \mathrm{m}$ were cut with a microtome up to a distance from the tip of about $1500 \mu \mathrm{m}$. Sections were mounted on polylysinetreated slides, deparaffinized in xylene and rehydrated through an ethanol series.

Immunological detection was performed as in Dell'Orto et al. (2002) with some modifications. Sections were incubated for $30 \mathrm{~min}$ at room temperature in $3 \% \mathrm{H}_{2} \mathrm{O}_{2}$, then blocked for $1 \mathrm{~h}$ in TBS (150 mM NaCl, $25 \mathrm{mM}$ Tris-HCl, pH 7.6) with $2 \%$ BSA $(\mathrm{w} / \mathrm{v})$. Sections were incubated overnight at $4^{\circ} \mathrm{C}$ in the same polyclonal antibodies used for Western blot after dilution 1:200
(anti-V-ATPase) and 1:300 (anti-V-PPase) in TBS with 0.5\% BSA. After $3 \times 5$ min washes in TBS, sections were incubated $2 \mathrm{~h}$ at room temperature with a biotinylated secondary antibody (anti-rabbit IgG biotin conjugate developed against goat, Sigma) diluted 1:200 in TBS with $0.5 \%$ BSA. After $3 \times 5$ min washes in TBS sections were incubated $30 \mathrm{~min}$ in extravidin-peroxidase (ExtrAvidin Peroxidase Staining Kit, Sigma) diluted 1:20. After $3 \times 5$ min washes in TBS sections were incubated $3-5 \mathrm{~min}$ in $0.05 \mathrm{M}$ acetate buffer pH 5.0 containing 5\% dimethylformamide, 0.04\% 3-amino-9ethylcarbazole (AEC) and $0.015 \% \mathrm{H}_{2} \mathrm{O}_{2}$ and finally washed in distilled water.

\section{RESULTS}

Cucumber and soybean plants grown in Fe-deprived nutrient solution for 8 and 11 days, respectively, showed highly chlorotic leaves and the typical Fe deficiency responses already described in previous works at the root level (Rabotti et al., 1995; Espen et al., 2000; Zocchi et al., 2007): in cucumber, a strong increase in both $\mathrm{Fe}$ reduction and $\mathrm{H}^{+}$extrusion, by induction of $\mathrm{FC}-\mathrm{R}$ and PM-ATPase activities respectively, enhanced activity of glycolytic enzymes and PEPC; in soybean, increased Fe reduction activity but weak acidification of the nutrient solution, no induction of the PM-ATPase activity, only slight increase of glycolytic enzymes and decrease of PEPC activity (data not shown).

For this reason, in order to investigate the role played by the two vacuolar $\mathrm{H}^{+}$pumps in the $\mathrm{pH}$-stat mechanism under Fe deficiency, vacuolar membrane vesicles were isolated from roots of both 8-day-old cucumber and 11-day-old soybean plants grown in the presence and in the absence of Fe. The V-ATPase activity, determined as the difference between ATP hydrolysis in the presence and in the absence of $50 \mathrm{mM}$ K-nitrate (nitrate-sensitive ATPase) was around $60 \%$ of the total ATPase activity for both cucumber and soybean preparations and is shown in Table 1. Both in cucumber and in soybean roots this activity is diminished under Fe deficiency. The V-PPase (Table 2) shows a similar behavior as the V-ATPase in Fe-deficient cucumber roots, lowering its phosphohydrolytic activity and thus contributing to the vacuole alkalization. On the contrary, in Fe-deficient soybean roots this activity is kept at the same level of the control or even slightly increased.

In order to verify whether the $\mathrm{H}^{+}$pump activities are regulated, under Fe deficiency, by decreasing their synthesis, Western bolt analysis was performed on tonoplast enriched fractions using

\section{Table 1 | Nitrate-sensitive $\mathrm{H}^{+}$-ATPase activity determined on tonoplast enriched fractions isolated from roots of 8-day-old cucumber and 11-day-old soybean plants grown in the presence (control) and in the absence of iron (-Fe).}

\begin{tabular}{|c|c|c|c|}
\hline AT & activity (n & ${ }^{-1}$ prot $\min ^{-1}$ ) & \\
\hline & Control & $-F e$ & $\%$ \\
\hline \multicolumn{4}{|l|}{ Cucumber } \\
\hline & $453 \pm 31$ & $290 \pm 18$ & -36 \\
\hline \multicolumn{4}{|l|}{ Soybean } \\
\hline & $168 \pm 12$ & $94 \pm 8$ & -44 \\
\hline
\end{tabular}

Results are the mean values ( $\pm S E$ ) of four experiments. 
Table 2 | Vacuolar $\mathrm{H}^{+}$-PPase activity determined on tonoplast enriched fractions isolated from roots of 8-day-old cucumber and 11-day-old soybean plants grown in the presence (control) and in the absence of iron $(-\mathrm{Fe})$.

\begin{tabular}{|c|c|c|}
\hline PPase activity (n & -1 prot $\min$ & \\
\hline Control & $-\mathrm{Fe}$ & $\%$ \\
\hline \multicolumn{3}{|l|}{ Cucumber } \\
\hline $215 \pm 15$ & $129 \pm 11$ & -40 \\
\hline \multicolumn{3}{|l|}{ Soybean } \\
\hline $179 \pm 15$ & $194 \pm 11$ & +8 \\
\hline
\end{tabular}

Results are the mean values ( $\pm S E$ ) of four experiments.

two polyclonal antibodies raised against the V- PPase polypeptide and the a subunit of the V-ATPase, respectively. For what concerns the V-ATPase (Figure 1) the antibody recognized a polypeptide with a molecular mass of about $95 \mathrm{kDa}$. The results are consistent with the measured activities, showing a decrease in the protein level in Fe-deficient roots of both cucumber and soybean. Also the V-PPase polypeptide level reflects the activity changes found under Fe deficiency, showing a decreased level of protein in cucumber roots and an accumulation in soybean (Figure 1).

Moreover, by using the same antibodies, an in situ immunological detection of V-ATPase and V-PPase proteins has been performed on subapical root sections of cucumber and soybean plants grown in the presence and in the absence of Fe (Figures 2 and 3 ) in order to localize this response at the histological level. Root sections in Figures 2 and 3 were cut at 500-900 $\mu \mathrm{m}$ from the tips, corresponding to the elongation zone. Root sections treated without the primary antibody appeared not stained, indicating that aspecific reactions attributable to the secondary antibody or to extravidin-peroxidase complex did not occur (data not shown).

Overall, it is evident that growth in the absence of Fe leads to the proliferation of root hairs in cucumber (Figures $2 \mathrm{~A}, \mathrm{C}$ and $3 \mathrm{~A}, \mathrm{C}$ ) and to increased root diameter in soybean (Figures 2B,D and 3B,D). This is in agreement with the well documented occurrence of root morphological modifications such as swollen root tips

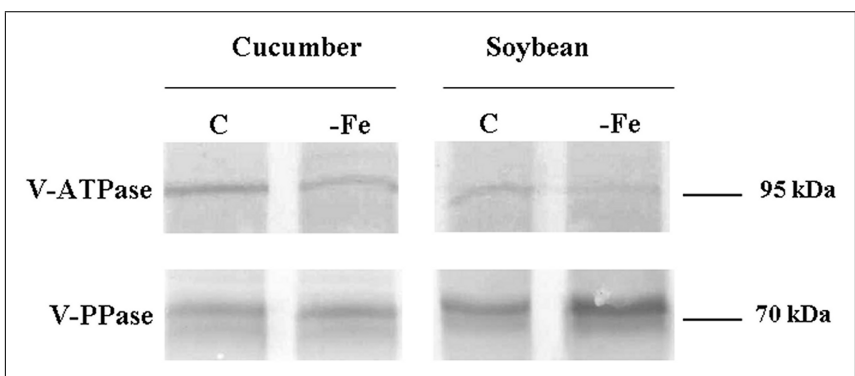

FIGURE 1 | Western blot analysis of proteins (10 $\mu \mathrm{L}$ per lane) present in tonoplast-enriched membrane vesicle fractions isolated from cucumber (left) and soybean (right) roots grown in the presence (C) and in the absence (-Fe) of Fe. Immunostaining was performed using polyclonal antibodies raised against the V-ATPase a subunit and the V-PPase polypeptide respectively. and root hairs formation in several Fe-deficient Strategy I plants (Schmidt, 1999; Dell'Orto et al., 2002). Under control growth conditions, the V-ATPase accumulated mainly in the external cell layers of root sections from both cucumber and soybean plants (Figures 2A,B). When grown in the absence of Fe, both cucumber and soybean root sections show a markedly reduced level of the V-ATPase (Figures 2C,D). The V-PPase protein is widely accumulated in root sections from the control cucumber plants (Figure 3A) staining all cortex layers, while under Fe deficiency a strong decrease in V-PPase protein expression occurs (Figure 3C), even more drastic than what detected by immunoblot analysis; soybean plants show a lower steady-state level of the V-PPase protein in the same root zone, but under Fe deficiency the PPase is strongly intensified, localizing particularly at the external cell layers and at the endodermis, suggesting an increase expression of the protein, in agreement with the Western blot result.

\section{DISCUSSION}

It is becoming more and more evident that, beyond the obligatory step of Fe reduction, the response efficiency in adapting to $\mathrm{Fe}$ low availability in Strategy I plants resides on other mechanisms which can be differently regulated in different genotypes. In particular, the highly differentiated aptitude to acidify the apoplast and the rhizosphere, by inducing the PM-ATPase activity, appears to explain the different tolerance exhibited by different genotypes to calcareous soils (Schmidt, 1999; Ksouri et al., 2006; M’sehli et al., 2009b).

By comparing the response to Fe deficiency in two Strategy I species, cucumber and soybean, it emerged that the different aptitudes to induce the PM-ATPase are accompanied by other differences, related to the root cell vacuolar composition: in cucumber roots, in which PM-ATPase and PEPC activities are strongly induced, the vacuole undergoes an alkalization and a depletion of $\mathrm{Pi}$, while in soybean, in which PM-ATPase and PEPC are weakly and/or not induced, the vacuolar $\mathrm{pH}$ is decreased and the Pi concentration increased (Espen et al., 2000; Zocchi et al., 2007). Thus, besides the already established role of PM-ATPase and PEPC in the pH-stat mechanism under Fe deficiency (Zocchi, 2006 and references therein), also the movements of Pi across the tonoplast could cooperate in balancing the cytosolic $\mathrm{pH}$, thanks to the buffering activity exerted by its $\mathrm{pH}$-dependent protonation/deprotonation reactions. So, to explain the different movements of Pi in soybean and cucumber, we hypothesized that in Fe-deficient soybean roots the net influx of Pi toward the vacuole would be sustained by the increased $\mathrm{H}^{+}$pumping activity of V-ATPase and/or V-PPase. On the contrary, in Fe-deficient cucumber roots we expected a decreased activity of the vacuolar proton pumps, perhaps to counterbalance the strong $\mathrm{H}^{+}$consumption by PM-ATPase and leading to a release of $\mathrm{H}_{2} \mathrm{PO}^{-}$which, by deprotonation in the cytosol, would cooperate in buffering the cytosolic $\mathrm{pH}$.

To test these hypotheses, tonoplast-enriched fractions were extracted from roots of cucumber and soybean plants grown in the presence and in the absence of Fe. In cucumber roots, Fe starvation induced a reduced activity of both the nitrate-sensitive ATPase and the PPase (Tables $\mathbf{1}$ and $\mathbf{2}$ ), as expected considering the high ATP and $\mathrm{H}^{+}$consumption by PM-ATPase and the increased vacuolar $\mathrm{pH}$ detected under these conditions (Rabotti and Zocchi, 


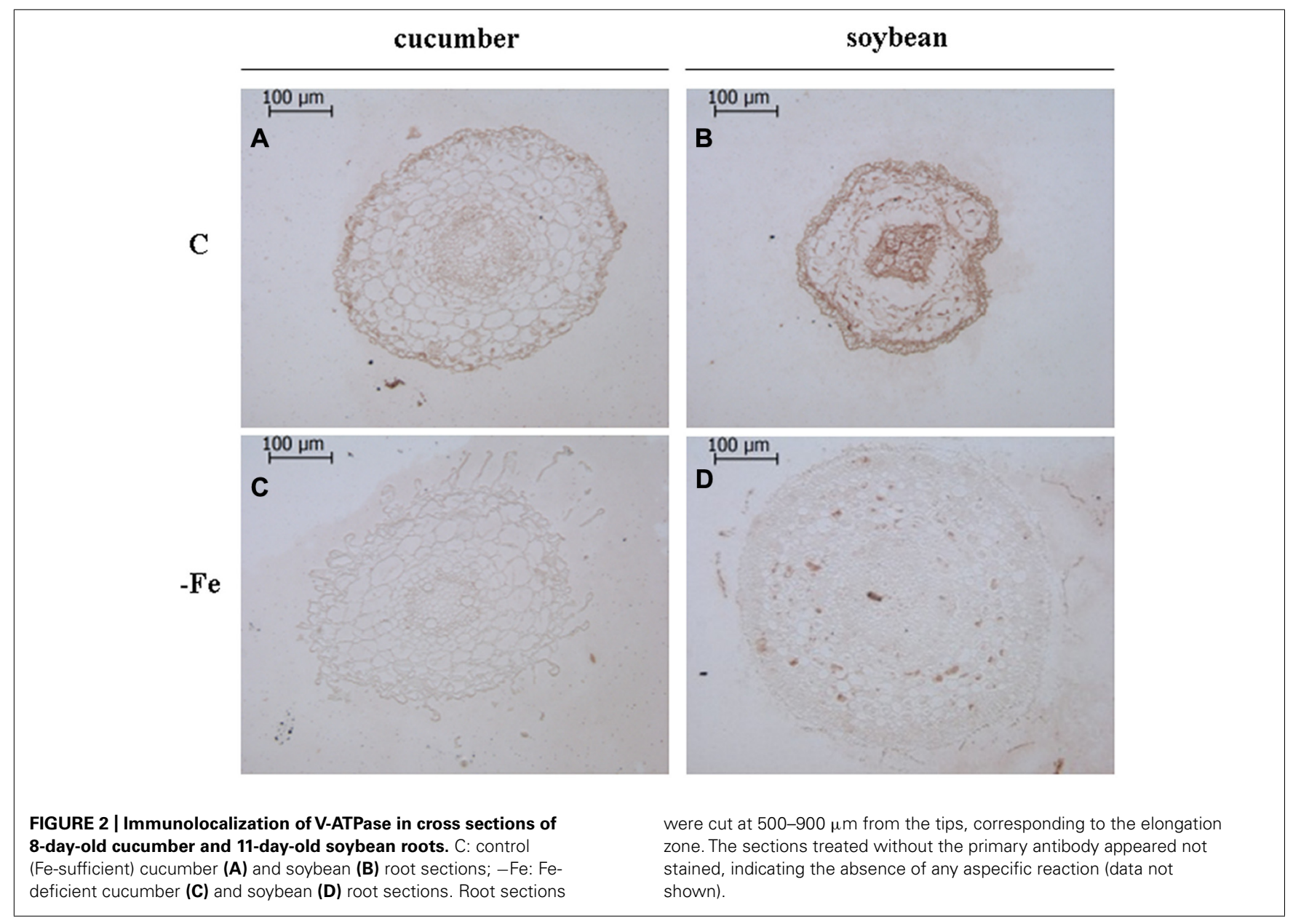

1994; Espen et al., 2000). This finding fits well with the scenario depicted in Figure 4A, resuming all the data available so far for cucumber: the increased PM-ATPase activity induces the alkalinization of the cytoplasm $\mathrm{pH}$ which, in turn, activates the PEPC (Zocchi, 2006). Moreover, the high need for $\mathrm{H}^{+}$is in part fulfilled also by the increased glycolysis rate; in part by the lower $\mathrm{H}^{+}$transport into the vacuole due to the reduced vacuolar pump activity, in part, as a consequence, by the net efflux of $\mathrm{H}_{2} \mathrm{PO}_{3}{ }^{-}$, which, at the cytosolic $\mathrm{pH}$ is subject to dissociation into $\mathrm{H}^{+}$and $\mathrm{HPO}_{3}{ }^{2-}$ (the pKa being 6.8).

For Fe-deficient soybean the proposed scenario is different, as shown in Figure 4B. In soybean roots the activity of the vacuolar pumps are differently affected by Fe deficiency: unexpectedly the V-ATPase activity is lowered more or less at the same degree as in cucumber, despite the low activity of the antagonistic PM-ATPase, showing to be not responsible for the acidification of the vacuole detected by Zocchi et al. (2007). On the contrary, the slight increase of the V-PPase activity found in Fe-deficient soybean roots, besides fitting well with the already mentioned vacuole acidification, is in agreement with several works reporting the increase of such activity under mineral deficiencies and various other stresses which affect the ATP synthesis rate (Maeshima, 2000 and references therein). In fact PPi, despite its high-energy phosphoanhydride bond, is indeed a low-cost substrate, generated as a by-product of several metabolic processes characteristic of actively growing cells, such as the synthesis of proteins, nucleic acid, and cellulose (Maeshima, 2000; Gaxiola etal., 2007). Thus, the ability of soybean roots to induce the V-PPase rather than the V-ATPase activity in response to a stress condition, which deeply affects the mitochondrial efficiency and thus the ATP supply (Vigani, 2012), could be interpreted as a metabolic plasticity leading to an alternative adaptive mechanism. In soybean roots, differently to what happens in cucumber the glycolysis rate does not increase significantly (Zocchi et al., 2007).

Protein amounts of V-ATPase subunit a and V-PPase were slightly reduced in the tonoplast fractions extracted from $\mathrm{Fe}$ deficient cucumber roots (Figure 1). Thus, the observed reduction in the activity of both tonoplast $\mathrm{H}^{+}$pumps can be, at least in part, attributed to changes in the expression of the encoding genes or in the amounts of proteins. As well, the amount of V-ATPase subunit a detected by Western blot in Fe-deficient soybean roots was lowered (Figure 1), consistently with the specific activity, while the amount of V-PPase (Figure 1), whose activity was found to be increased by Fe starvation, was higher. This is not an obvious result since it has been found, especially for the V-PPase, that the activity changes in response to nutritional stresses are due to post-translational modulation rather than to increased amount of 

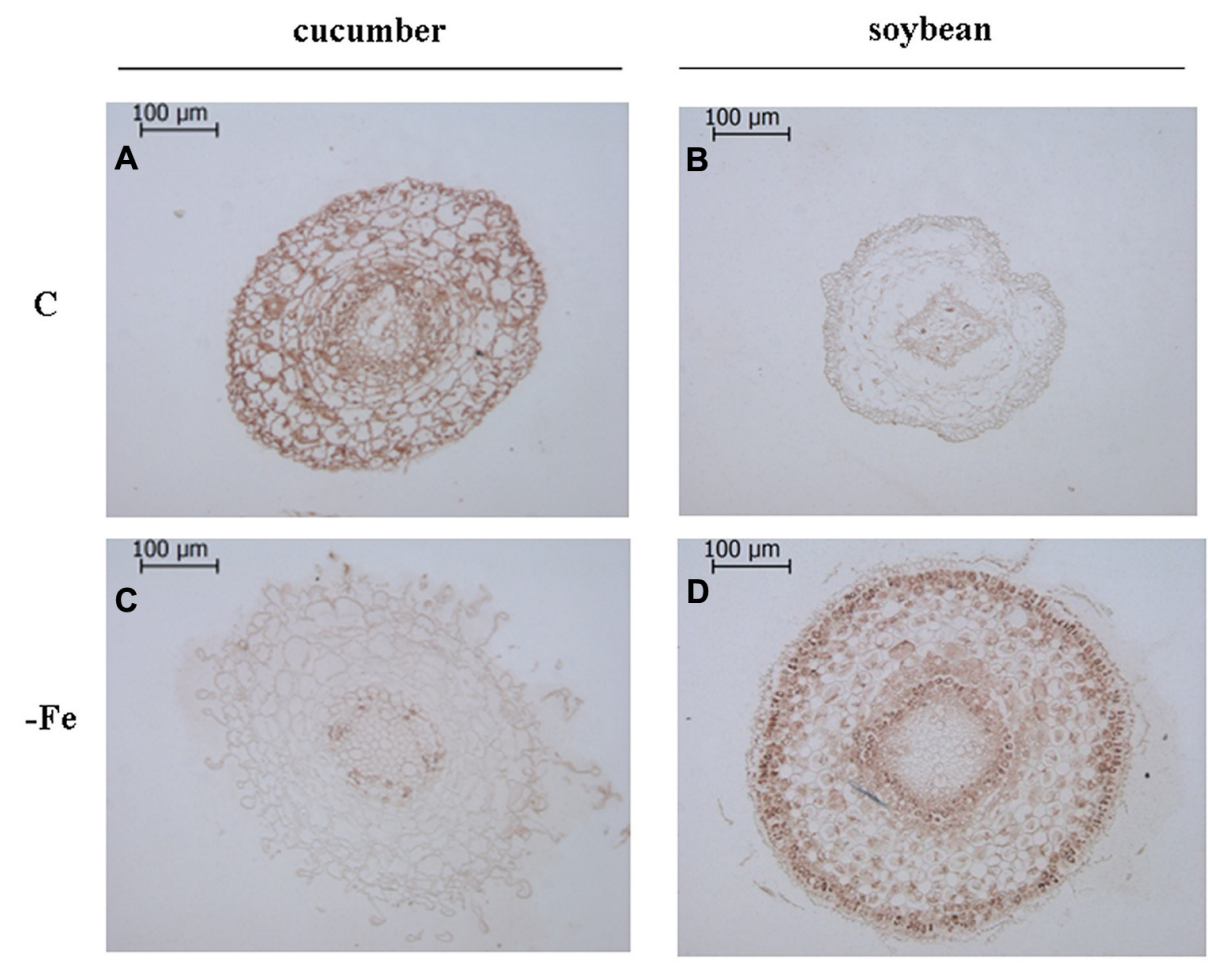

FIGURE 3 | Immunolocalization of V-PPase in cross sections of 8-day-old cucumber and 11-day-old soybean roots. C: control (Fe-sufficient) cucumber (A) and soybean (B) root sections; - Fe: Fe-deficient cucumber (C) and soybean (D) root sections. Root sections were cut at 500-900 $\mu \mathrm{m}$ from the tips, corresponding to the elongation zone. The sections treated without the primary antibody appeared not stained, indicating the absence of any aspecific reaction (data not shown). the proteins (Maeshima, 2000; Ohnishi et al., 2007; Kabała and Janicka-Russak, 2011).

Several post-translational regulation mechanisms have been proposed both for V-ATPase and for V-PPase in plants: one of the possible mechanisms involved in the regulation of $\mathrm{V}$ ATPase is reversible phosphorylation (Liu et al., 2004; McCubbin etal., 2004; Hong-Hermesdorf et al., 2006); moreover, a phosphorylation-dependent specific interaction with 14-3-3 protein has been found to be involved (Klychnikov et al., 2007). Since a putative 14-3-3 interaction motif has been identified also in V-PPase from Vitis vinifera, the existence of a coordinated regulation of the three $\mathrm{H}^{+}$pumps involved in $\mathrm{pH}$-homeostasis in the cytosol can be postulated (Gaxiola et al., 2007). The posttranslational regulation of plant V-ATPase has been reviewed by Ratajczak (2000).

It has been found that in young growing tissues in which the anabolism is high, such as for instance seedling hypocotyls, the $\mathrm{V}$-PPase activity determined on vacuolar membrane fraction was higher respect to the V-ATPase activity, due to a higher content of the former enzyme, this being consistent with the availability of large amounts of PPi in such tissues. On the contrary, in mature cells, in which the anabolism decreases leading to a lower PPi availability, V-PPase activity has been found to be lower than that of V-ATPase (Maeshima, 2000 and references therein). In this work the immunohistochemical technique allowed us to localize the changes in protein amounts in the root portion in which the response to Fe deficiency actually occurs, i.e., the sub apical region, corresponding to the elongation zone, characterized by actively growing tissues and thus by a high anabolic activity. Under Fe-sufficient conditions the relative enrichment of the V-PPase protein respect to the V-ATPase could be seen only in cucumber roots; while in soybean roots the V-ATPase seems to be more expressed than the V-PPase. Moreover, the differences found between Fe-sufficient and Fe-deficient roots in the expression level of the two proteins appear to be stronger than what evidenced by western blot. This could be probably explained by the fact that the tonoplast enriched fraction was obtained from the whole root system, leading to a dilution effect in the control samples, since the two proton pumps, but especially the V-PPase, are particularly expressed in the actively growing tissues (Nakanishi and Maeshima, 1998; Maeshima, 2000; Gaxiola et al., 2007) as the root meristems and elongation zones are. With this regard, the immunohistochemical approach seems provide better assessment, since it allows to detect the expression of the two proton pumps in a more limited region, in which the Strategy I responses actually take place (Dell'Orto et al., 2002; Schmidt et al., 2003).

Overall, the results obtained in this work, together with those previously reported by Espen et al. (2000) and Zocchi et al. (2007) suggest that cucumber and soybean, although both adopting the Strategy I for Fe uptake, follow different models for what concerns the metabolic adaptations needed to sustain the response to $\mathrm{Fe}$ 

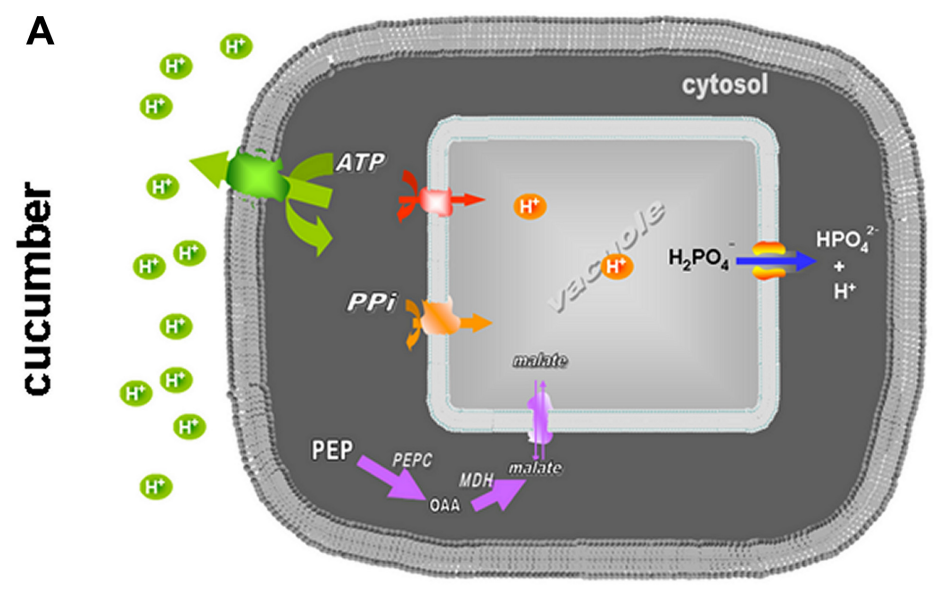

B

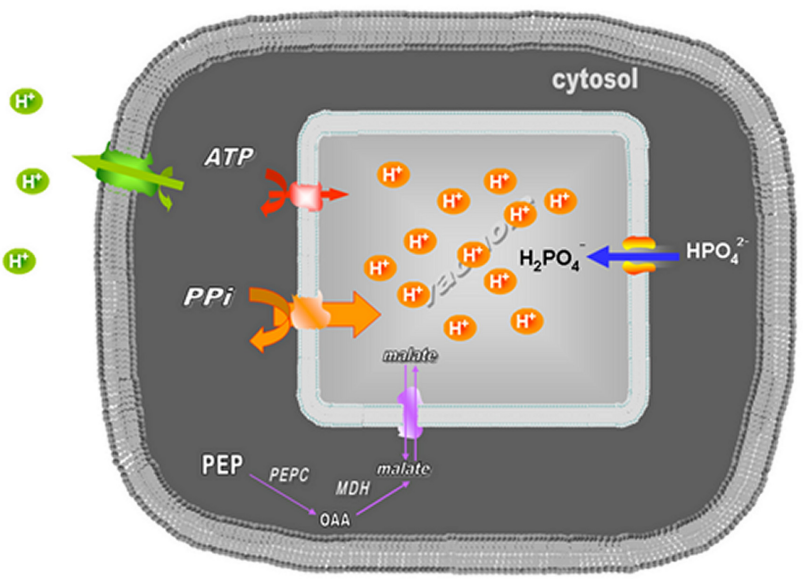

FIGURE 4 | Representation of the different roles of the vacuolar proton pumps and Pi movements across the tonoplast in cucumber (A) and soybean (B) roots under Fe deficiency. The activities of the PM-ATPase, V-ATPase, V-PPase, and PEPC are visualized as differently marked lines; the net Pi fluxes are described through the arrow orientation.

starvation. In particular these two species resulted to differently manage the cellular $\mathrm{pH}$ homeostasis by differently modulating the $\mathrm{V}$-PPase and, as a consequence, by differently regulating the Pi fluxes across the tonoplast.

It is still to be elucidated how the vacuolar proton pumps regulation is coordinated with that of the other activities involved in the pH-stat of the cell, i.e., the PM-ATPase and the PEPC. Moreover, also the fluxes of malate produced by PEPC across the tonoplast could be involved in the cytosolic $\mathrm{pH}$ homeostasis as proposed by Martinoia et al. (2007) and by Figure 4, since under Fe deficiency the malate concentration is strongly increased in

\section{REFERENCES}

Ames, B., and N. (1966). Assay of inorganic phosphate, totals phosphate, and phosphatases. Methods Enzymol. 8, 115-118. doi: 10.1016/00766879(66)08014-5

Bienfait, H. F., Lubberding, H. J., Heutink, P., Lindner, L., Visser, J., Kaptein, R., etal. (1989).
Rhizosphere acidification by iron deficient bean plants: the role of trace amounts of divalent metal ions. Plant Physiol. 90, 359-364. doi: 10.1104/pp.90.1.359

Bradford, M. M. (1976). A rapid and sensitive method for the quantitation of microgram quantities of protein utilizing the principle of protein-dye

several dicotyledonous species, among which cucumber (Rabotti et al., 1995). Future work should then be addressed to elucidate the role of malate and the regulation of the vacuolar malate transporter, since acidification of the plant cytosol has been found to stimulate the expression of the gene encoding for it in Arabidopsis (AttDT; Hurth et al., 2005).

\section{ACKNOWLEDGMENT}

We wish to thank Dr. Maeshima (Nagoya University, Japan) for the kind gift of the antibodies against V-ATPase and V-PPase.

binding. Anal. Biochem. 72, 248-254. doi: 10.1016/0003-2697(76)90527-3

Davies, D. D. (1973). Control of and by pH. Symp. Soc. Exp. Biol. 27, 513-520.

Dell'Orto, M., Pirovano, L., Villalba, J. M., González Reyes, J. A., and Zocchi, G. (2002). Localization of the plasma membrane $\mathrm{H}^{+}$-ATPase in Fe-deficient cucumber roots by immunodetection. Plant Soil 241, 11-17. doi: 10.1023/A:101 6030514200

De Nisi, P., and Zocchi, G. (2000). Phosphoenolpyruvate carboxylase in cucumber (Cucumis sativus L.) roots under iron deficiency: activity and kinetic characterization. 
J. Exp. Bot. 51, 1903-1909. doi: 10.1093/jexbot/51.352.1903

Espen, L., Dell'Orto, M., De Nisi, P., and Zocchi, G. (2000). Metabolic responses in cucumber (Cucumis sativus L.) roots under Fe deficiency: a 31P-nuclear magnetic resonance in vivo study. Planta 210, 985-992. doi: 10.1007/s004250050707

Gaxiola, R. A., Palmgren, M. G., and Schumacher, K. (2007). Plant proton pumps. FEBS Lett. 581, 2204 2214. doi: 10.1016/j.febslet.2007. 03.050

Hedrich, R., and Marten, I. (2006). 30 year progress of membrane transport in plants. Planta 224, 725-739. doi: 10.1007/s00425-006-0341-x

Hong-Hermesdorf, A., Brux, A., Gruber, A., Gruber, G., and Schumacher, K. (2006). A WNK kinase binds and phosphorylates V-ATPase subunit C. FEBS Lett. 580, 932 939. doi: 10.1016/j.febslet.2006. 01.018

Hurth, M. A., Suh, S. J., Kretzschmar, T., Geis, T., Bregante, M., Gambale, F., et al. (2005). Impaired $\mathrm{pH}$ homeostasis in Arabidopsis, lacking the vacuolar dicarboxylate transporter and analysis of carboxylic acid transport across the tonoplast.Plant Physiol. 137, 901-910. doi: 10.1104/pp.104. 058453

Ivanov, R., Brumbarova, T., and Bauer, P. (2012). Fitting into the harsh reality: regulation of iron deficiency responses in dicotyledonous plants. Mol. Plant 5, 27-42. doi: $10.1093 / \mathrm{mp} / \mathrm{ssr} 065$

Landsberg, E. C. (1986). Function of rhizodermal transfer cells in Fe stress response mechanism of Capsicum annum L. Plant Physiol. 82, 511-517. doi: 10.1104/pp.82.2.511

Kabała, K., and Janicka-Russak, M. (2011). Differential regulation of vacuolar $\mathrm{H}^{+}$-ATPase and $\mathrm{H}^{+}$-PPase in Cucumis sativus roots by zinc and nickel. Plant Sci. 180, 531539. doi: 10.1016/j.plantsci.2010. 11.013

Kim, S. A., and Guerinot, M. L. (2007). Mining iron: iron uptake and transport in plants. FEBS Lett. 581, 2273-2280. doi: 10.1016/j.febslet.2007.04.043

Klychnikov, O. I., Lill, K. W., Li, H., and de Boer, A. H. (2007). The V-ATPase from etiolated barley (Hordeum vulgare L.) shoots is activated by blue light and interacts with 14-3-3 proteins. J. Exp. Bot. 58, 1013-1023. doi: 10.1093/jxb/erl261

Kobae, Y., Uemura, T., Sato, M. H., Ohnishi, M., Mimura, T., and Maeshima, M. (2004). Zinc transporter of Arabidopsis thaliana
AtMTP1 is localized to vacuolar membranes and implicated in zinc homeostasis. Plant Cell Physiol. 45, 1749-1758. doi: 10.1093/pcp/ pci015

Ksouri, R., M'rah, S., Gharsalli, M., and Lachaâl, M. (2006). Biochemical responses to true and bicarbonate induced iron deficiency in grapevine genotypes. J. Plant Nutr. 29, 305-315. doi: 10.1080/019041605 00476897

Landsberg, E. C. (1986). Function of rhizodermal transfer cells in Fe stress response mechanism of Capsicum annum L. Plant Physiol. 82, 511-517. doi: 10.1104/pp.82.2.511

Liu, G. S., Chen, S., Chen, J., and Wang, X. C. (2004). Identification of the phosphorylation site of the V-ATPase subunit A in maize roots. Acta Bot. Sin. 46, 428-435.

López-Millán, A. F., Morales, F., Andaluz, S., Gogorcena, Y., Abadía, A., De Las Rivas, J., et al. (2000). Responses of sugar beet roots to iron deficiency. Changes in carbon assimilation and oxygen use. Plant Physiol. 124, 885-897. doi: 10.1104/pp.124.2.885

Maeshima, M. (2000). Vacuolar $\mathrm{H}^{+}$-pyrophosphatase. Biochim. Biophys. Acta 1465, 37-51. doi: 10.1016/S0005-2736(00)00130-9

Maeshima, M. (2001). Tonoplast transporters: organization and function. Annu. Rev. Plant Physiol. Plant Mol. Biol. 52, 469-497. doi: 10.1146/annurev. arplant.52.1.469

Maeshima, M., and Yoshida, S (1989). Purification and properties of vacuolar membrane protontranslocating inorganic pyrophosphatase from mung bean. J. Biol. Chem. 264, 20068-20073.

Marschner, H., Römheld, V., and Kissel, M. (1986). Different strategies in higher plants in mobilization and uptake of iron. $J$. Plant Nutr. 9, 695-713. doi: 10.1080/01904168609363475

Martinoia, E., Maeshima, M., and Neuhaus, H. E. (2007). Vacuolar transporters and their essential role in plant metabolism. J. Exp. Bot. 58, 83-102. doi: $10.1093 / \mathrm{jxb} /$ erl183

Massonneau, A., Martinoia, E. Dietz, K.-J., and Mimura, T. (2000). Phosphate uptake across the tonoplast of intact vacuoles isolated from suspension-cultured cells of Catharanthus roseus (L.) G. Don. Planta 211, 390-395. doi: 10.1007/s004250000297

McCubbin, A. G., Ritchie, S. M. Swanson, S. J., and Gilroy, S.
(2004). The calcium-dependent protein kinase HvCDPK1 mediates the gibberellic acid response of barley aleurone through regulation of vacuolar function. Plant J. 39, 206-218. doi: 10.1111/j.1365-313X 2004.02121.x

M'sehli, W., Dell'Orto, M., Donnini, S., De Nisi, P., Zocchi, G., Abdelly, C., et al. (2009a). Variability of metabolic responses and antioxidant defense in two lines of Medicago cil iaris to Fe deficiency. Plant Soil 320 219-230. doi: 10.1007/s11104-0089887-7

M'sehli, W., Dell'Orto, M., De Nisi, P., Donnini, S., Abdelly, C., Zocchi, G. et al. (2009b). Responses of two ecotypes of Medicago ciliaris to direct and bicarbonate-induced iron deficiency conditions. Acta Physiol. Plant. 31 667-673. doi: 10.1007/s11738-0090288-1

Nakanishi, Y., and Maeshima, M. (1998). Molecular cloning of vacuolar $\mathrm{H}^{+}$-pyrophosphatase and its developmental expression in growing hypocotyl of mung bean. Plant Physiol. 116, 589-597. doi: 10.1104/pp.116.2.589

Ohnishi, M., Mimura, T., Tsujimura T., Mitsuhashi, N., WashitaniNemoto, S., Maeshima, M., etal. (2007). Inorganic phosphate uptake in intact vacuoles isolated from suspension-cultured cells of Catharanthus roseus (L.) G. Don under varying $\mathrm{Pi}$ status. Planta 225, 711-718. doi: 10.1007/s00425-0060379-9

Rabotti, G., De Nisi, P., and Zocchi, G. (1995). Metabolic implications in the biochemical responses to iron deficiency in cucumber (Cucucmis sativus L.) roots. Plant Physiol. 107, 1195-1199. doi: 10.1104/pp.107. 4.1195

Rabotti, G., and Zocchi, G. (1994). Plasma membrane-bound $\mathrm{H}^{+}$-ATPase and reductase activities in Fe-deficient cucumber roots. Physiol. Plant. 90, 779785. doi: 10.1111/j.1399-3054 1994.tb02537.x

Ratajczak, R. (2000). Structure, function, and regulation of the plant vacuolar H.-translocating ATPase. Biochim. Biophys. Acta 1465, 17-36. doi: 10.1016/S0005-2736(00) 00129-2

Rea, P. A., and Poole, R. J. (1985). Proton-translocating inorganic pyrophosphatase in red beet (Beta vulgaris L.) tonoplast vescicles. Plant Physiol. 77, 46-52. doi: 10.1104/pp.77.1.46

Rodríguez-Celma, J., Lin, W. D., Fu, G. M., Abadía, J., López-Míllán,
A. F., and Schmidt, W. (2013). Mutually exclusive alterations in secondary metabolism are critical for the uptake of insoluble iron compounds by Arabidopsis and Medicago truncatula. Plant Physiol. doi: 10.1104/pp.113.220426 [Epub 2013 Jun 4].

Schmidt, W. (1999). Mechanisms and regulation of reduction based iron uptake in plants. New Phytol. 141, 1-26. doi: 10.1046/j.14698137.1999.00331.x

Schmidt, W. (2006). "Iron stress responses in roots of Strategy I plants," in Iron Nutrition in Plants and Rhizospheric Microorganisms, eds L. L. Barton and J. Abadía (Dordrecht: Springer), 229-250.

Schmidt, W., Michalke, W., and Schikora, A. (2003). Proton pumping by tomato roots. Effect of $\mathrm{Fe}$ deficiency and hormones on the activity and distribution of plasma membrane $\mathrm{H}^{+}$-ATPase in rhizodermal cells. Plant Cell Environ. 26, 361-370. doi: 10.1046/j.13653040.2003.00967.x

Schumacher, K. (2006). Endomembrane proton pumps: connecting membrane and vesicle transport. Curr. Opin. Plant Biol. 9, 595-600. doi: 10.1016/j.pbi.2006. 09.001

Vigani, G. (2012). Discovering the role of mitochondria in the iron deficiency-induced metabolic responses of plants. J. Plant Physiol. 169, 1-11. doi: 10.1016/j.jplph.2011. 09.008

Ward, J. M., and Sze, H. (1992). Subunit composition and organization of the vacuolar $\mathrm{H}^{+}$-ATPase from oat roots. Plant Physiol. 99, 170-179. doi: 10.1104/pp.99. 1.170

Zocchi, G. (2006). "Metabolic changes in iron-stressed dicotyledonous plants," in Iron Nutrition in Plants and Rhizospheric Microorganisms, eds L. L. Barton and J. Abadía (Dordrecht: Springer), 359-370.

Zocchi, G., De Nisi, P., Dell'Orto, M., Espen, L., and Marino Gallina, P. (2007). Iron deficiency differently affects metabolic responses in soybean roots. J. Exp. Bot. 58, 993-1000. doi: 10.1093/jxb/ erl259

Conflict of Interest Statement: The authors declare that the research was conducted in the absence of any commercial or financial relationships that could be construed as a potential conflict of interest. 
Received: 04 June 2013; paper pending published: 17 June 2013; accepted: 01 August 2013; published online: 27 August 2013.

Citation: Dell'Orto $M$, De Nisi P, Vigani $G$ and Zocchi G (2013) Fe deficiency differentially affects the vacuolar proton pumps in cucumber and soybean roots. Front. Plant Sci. 4:326. doi: 10.3389/fpls.2013. 00326

This article was submitted to Plant Nutri tion, a section of the journal Frontiers in Plant Science.
Copyright (C) 2013 Dell'Orto, De Nisi, Vigani and Zocchi. This is an openaccess article distributed under the terms of the Creative Commons Attribution License (CC BY). The use, distribution or reproduction in other forums is permitted, provided the original author(s) or licensor are credited and that the original publication in this journal is cited, in accordance with accepted academic practice. No use, distribution or reproduction is permitted which does not comply with these terms. 